\title{
Influência da Geometria e Umidade de Colunas de Solo na Biodegradação de Filmes de PCL
}

\author{
Suely P. C. Gonçalves, Adriana de Campos, Sandra M. Martins-Franchetti \\ Departamento de Bioquímica e Microbiologia, UNESP
}

\begin{abstract}
Resumo: Filmes de poli(ع-caprolactona) (PCL) foram preparados por compressão a quente e investigados com respeito a sua biodegradação em diferentes colunas de solo, após 60 dias. A morfologia e estrutura dos filmes, após os diferentes tratamentos, foram verificadas através de medidas de perda de massa, espectroscopia no infravermelho com transformada de Fourier (FTIR), calorimetria exploratória diferencial (DSC), termogravimetria (TG) e microscopia eletrônica de varredura (MEV). Os filmes de PCL sofreram biodegradação, principalmente na fase amorfa, atribuídas a quebras das ligações ésteres da cadeia polimérica, devido à ação de exo-enzimas dos microrganismos do solo. Os fatores abióticos, tais como temperatura, $\mathrm{pH}$, quantidade de oxigênio e principalmente tipo de coluna de solo e umidade, foram aspectos considerados relevantes no processo de biodegradação dos filmes de PCL em solo.
\end{abstract}

Palavras-chave: Poli(E-caprolactona), solo, biodegradação, microrganismos.

\section{Influence of Geometry and Humidity of Soil Columns in the Biodegradation of PCL Films}

Abstract: Poly ( $\varepsilon$-caprolactone) (PCL) films were prepared by melt-pressing and investigated with respect to their biodegradation in different soil columns after 60 days. The morphology and structure of the films, after various microbial treatments, were studied with measurements of mass loss, Fourier transform infrared spectroscopy (FTIR), differential scanning calorimetry (DSC), thermogravimetry ( TG) and scanning electron microscopy (SEM). The PCL films underwent biodegradation, mainly in the amorphous phase, attributed to breaking of ester bonds of the polymer chain due to the action of exo-enzymes from soil microorganisms. The abiotic factors such as temperature, $\mathrm{pH}$, oxygen content and principally soil column type and humidity were considered important aspects for the biodegradation process on the PCL films in soil.

Keywords: Poly(E-caprolactone), soil, biodegradation, microorganisms.

\section{Introdução}

Microrganismos, como bactérias e fungos estão envolvidos na degradação de plásticos naturais e sintéticos ${ }^{[1]}$. A biodegradação de materiais plásticos ocorre ativamente sob diferentes condições de solo de acordo com suas propriedades, pois os microrganismos responsáveis pela degradação diferem uns dos outros pela morfologia, capacidade metabólica e condições ótimas de crescimento. A biodegradação é regida por diferentes fatores, que incluem as características do polímero, tipo de organismo, e a natureza do pré-tratamento. Os polímeros são substratos potenciais para a ação de microrganismos heterotróficos ${ }^{[2]}$.

Algumas características polímericas, tais como a mobilidade, taticidade, cristalinidade, massa molar e o tipo de grupos funcionais e substituintes presentes na sua estrutura, desempenham um papel importante na sua degradação $0^{[3,4]}$. Durante a degradação o polímero é primeiramente convertido em seus monômeros, que posteriormente, mas não necessariamente podem ser mineralizados. A maioria dos polímeros é constituída por moléculas longas para atravessar as membranas celulares, por isso primeiramente são despolimerizadas em monômeros que são absorvidos e biodegradados no interior das células microbianas. A quebra inicial de um polímero pode ser o resultado de uma variedade de fatores físicos e biológicos ${ }^{[5]}$. Fatores físicos tais como o aquecimento/resfriamento, congelamento, descongelamento, ou umedecimento/secagem, podem causar danos mecânicos, como a quebra dos materiais poliméricos ${ }^{[6]}$.

Poli(caprolactona) é um poliéster alifático sintético, biodegradável e não-tóxico, um exemplo de polímero biocompatível, que é completamente biodegradável dentro do corpo após a interação com fluidos corporais, enzimas e células, e, portanto, adequado para aplicações biomédicas ${ }^{[7]}$.
Testes de biodegradação de materiais poliméricos podem ser realizados por diferentes métodos e ambientes ${ }^{[8]}$. Em geral, nos estudos de biodegradação em solo natural, não há um protocolo referente à quantidade e condições do solo. Este artigo investiga a biodegradação de filmes de PCL, realizada em colunas de solo, com geometria diferentes e sistemas de umidade diferentes (por gotejamento e por capilaridade), através de medidas de perda de massa, FTIR, DSC, TG e MEV.

\section{Materiais e Métodos}

\section{Materiais}

Neste estudo foi utilizado o polímero poli( $\varepsilon$-caprolactona) (PCL), com massa molar de 85.000 g.mol ${ }^{-1}$, Solvay-K6800.

\section{Preparo dos filmes}

Os filmes poliméricos foram obtidos em prensa hidráulica, marca Solab com aquecimento à temperatura de $180{ }^{\circ} \mathrm{C}$ e submetidos à pressão de $89.10 \mathrm{kgf} . \mathrm{cm}^{-2}$ por 5 minutos e resfriados em temperatura ambiente $\left(25^{\circ} \mathrm{C}\right)$.

\section{Métodos de biodegradação}

As amostras de solo utilizadas para os ensaios do tratamento microbiano foram coletadas de uma área do jardim do Campus UNESP/Rio Claro. As amostras dos solos foram peneiradas em malha grossa $(3 \mathrm{~mm})$. Foram realizados dois diferentes ensaios de biodegradação em colunas de solo. Em um dos ensaios foram, utilizadas caixas $(36 \times 56 \times 31 \mathrm{~cm}$, como colunas de solo $)$ e a

Autor para correspondência: Sandra M. Martins-Franchetti, Departamento de Bioquímica e Microbiologia, Instituto de Biociências, 
umidade foi controlada por um sistema de gotejamento de água, na parte superior das caixas (umidade de $40 \%$ ). No outro ensaio, foram utilizadas garrafas plásticas $(25 \times 13 \mathrm{~cm})$, com furos distribuídos uniformemente, para auxiliar na oxigenação do solo e na atividade microbiana, sendo o sistema umedecido por capilaridade, através de dois furos na base inferior da garrafa, mantendo a umidade de $48 \%$. A umidade do solo foi determinada, em porcentagem, pela diferença dos pesos dos solos antes e após a secagem em estufa ${ }^{[9]}$. Os filmes poliméricos, em duplicatas, foram enterrados nos dois sistemas contendo solo (Figura 1a e b). No sistema por gotejamento (Figura 1a) foram enterrados vários filmes de polímeros diferentes em duplicatas. No sistema por capilaridade (Figura 1b) foi enterrada apenas uma amostra do filme de PCL. As amostras, após tratamento microbiano, foram cuidadosamente limpas e colocadas em dessecador por 48 horas, para análises posteriores.

\section{Teste de hidrólise química}

Este teste é necessário para determinar se o polímero - PCL sofre quebras hidrolíticas, causadas pela umidade e $\mathrm{pH}$ do solo. Amostras dos filmes de PCL $(1,5 \times 1,5 \mathrm{~cm})$ foram incubadas em solução tampão fosfato $(0.2 \mathrm{M}), 15 \mathrm{~mL}, \mathrm{pH} 5.8$, semelhante ao $\mathrm{pH}$ do solo, e incubadas a $28{ }^{\circ} \mathrm{C}$, em frascos âmbar. As amostras dos filmes, em duplicatas, foram retiradas a cada 15 dias, e foram lavadas com água, secas a vácuo e submetidas às técnicas de caracterização do polímero citadas a seguir.

\section{Métodos de análise}

\section{Infravermelho (FTIR)}

Os espectros de infravermelho dos filmes de PCL foram obtidas em temperatura ambiente, usando espectrofotômetro Shimadzu FTIR-8300 com resolução $4 \mathrm{~cm}^{-1}$, faixa de $4000-400 \mathrm{~cm}^{-1}$.

\section{Calorimetria exploratória diferencial (DSC)}

As amostras (cada um pesando aproximadamente $6 \mathrm{mg}$ ) foram analisadas em um calorímetro diferencial TA Instruments DSC2910 (no IFSC-USP). As medidas foram realizadas na faixa de temperatura de 25 a $250{ }^{\circ} \mathrm{C}$, em uma razão de aquecimento de $10{ }^{\circ} \mathrm{C} / \mathrm{min}$, e em atmosfera de nitrogênio a $50 \mathrm{~mL} / \mathrm{min}$.

\section{Microscopia Eletrônica de Varredura (MEV)}

As morfologias dos filmes produzidos, foram avaliadas utilizando-se um microscópio eletrônico de varredura modelo Zeiss DSM 940 - A, operando a 4 kV (ESALQ / USP - Piracicaba/SP). As amostras analisadas por microscopia eletrônica de varredura foram metalizadas com ouro, metalizador MED 010 - Balzers e o suporte foi feito com fita de carbono.

\section{Resultados e Discussão}

Os filmes obtidos apresentaram-se transparentes, uniformes e com aproximadamente $100 \mu \mathrm{m}$ de espessura. Os espectros de absorção no FTIR dos filmes de PCL, antes e após o tratamento microbiano em solo, após 30 dias nas diferentes colunas de solo, estão apresentados na Figura 2. As relações das intensidades de absorção calculadas pelas bandas espectrais dos filmes de PCL original e biotratado, foram verificadas tomando-se como referência, a banda de padrão interno a $2931 \mathrm{~cm}^{-1}$, por se manter constante, sem alteração da banda, após o tratamento microbiano.

Os filmes de PCL tratados em sistema de coluna de solo por capilaridade, durante 30 dias, não apresentaram mudanças, tais como deslocamentos de bandas, aparecimento de novas bandas. Entretanto, houve diminuição da banda a $1725 \mathrm{~cm}^{-1}$, indicativa de perda de grupos carbonílicos na fase amorfa ${ }^{[10]}$ e com 60 dias, houve grande distorção espectral, devido à opacidade do filme.

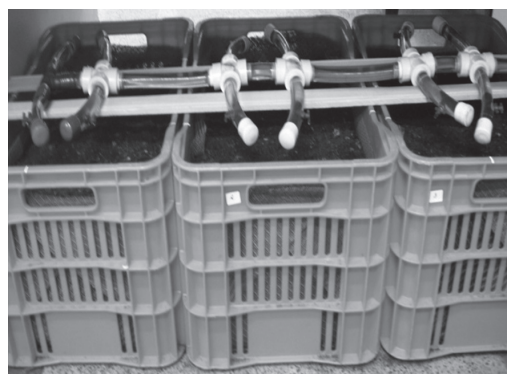

(a)

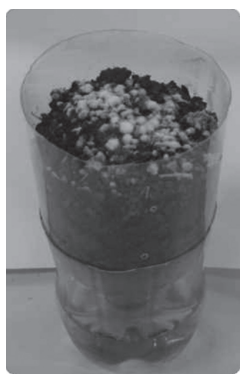

(b)
Figura 1. Coluna de solo a) sistema por gotejamento; e b) capilaridade.

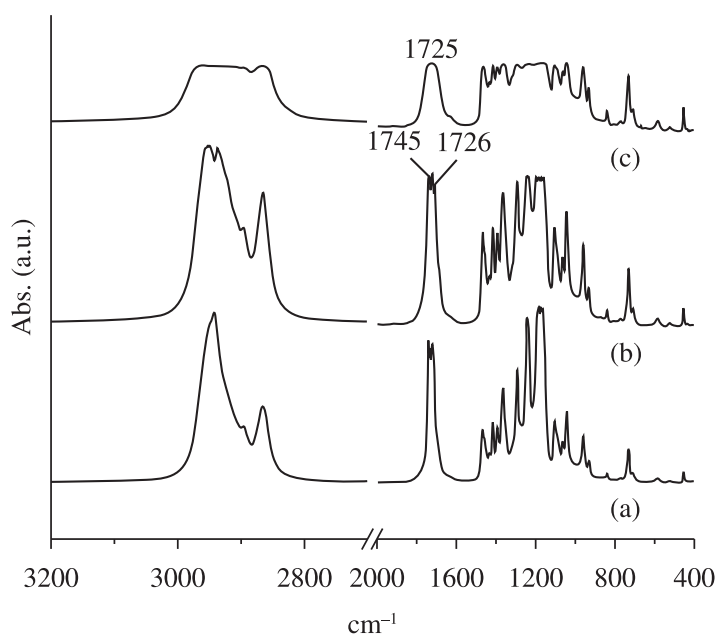

Figura 2. Espectro de FTIR: a) PCL original; b) biotratado em solo úmido por gotejamento; e c) biotratado em solo úmido por capilaridade.

Para os filmes submetidos ao tratamento microbiano na coluna de solo umedecida por gotejamento, observamos deslocamentos na faixa de 2930-2950 $\mathrm{cm}^{-1}$, atribuídas aos estiramentos simétrico e assimétrico do grupo $\mathrm{CH}_{2}$. Houve diminuição de intensidade relativa da carbonila na fase amorfa $\left(1745\right.$ e $\left.1737 \mathrm{~cm}^{-1}\right)$, relacionada à quebras das ligações éster do PCL. Geralmente a degradação ocorre primeira, e preferencialmente na fase amorfa do polímero ${ }^{[11]}$. Os filmes submetidos ao tratamento por hidrólise química não apresentaram alterações espectrais, indicando que as mudanças ocorridas no polímero, foram devidas à ação microbiana e não à reações químicas.

As curvas de DSC dos filmes de PCL original e biotratados em solo estão apresentadas na Figura 3. As temperaturas e entalpias de fusão, juntamente com os cálculos das porcentagens de cristalinidade estão apresentados na Tabela 1. O grau de cristalinidade dos filmes de PCL foi calculado a partir dos dados de calor de fusão teórico de cada polímero, hipoteticamente $100 \%$ cristalino, $\Delta \mathrm{H}_{\mathrm{f}}^{0}=136 \mathrm{~J}^{\mathrm{J}} \mathrm{g}^{-1[12]}$.

Os filmes de PCL, após 30 dias de tratamento microbiano em solo, tanto no sistema por capilaridade, apresentaram aumento da temperatura de fusão (Figura 3) e do grau de cristalinidade (Tabela 1). O aumento do grau de cristalinidade e da temperatura de fusão indicam reorganização das cadeias poliméricas remanescentes após o consumo da fase amorfa e aumento de espessura das lamelas, respectivamente, diferentemente do que ocorre, por exemplo, no caso da degradação do PLLA por hidrólise, em que há quemicristalização de segmentos de cadeia, e a formação de novos cristais com $\mathrm{T}_{\mathrm{f}}$ menor ${ }^{[13,14]}$. Aumento na fração cristalina de filmes de PCL foi também observado durante a biodegradação de filmes de PCL em água do $\operatorname{mar}^{[15]}$. Por gotejamento, o aumento do grau de cristalinidade não foi expressivo. 


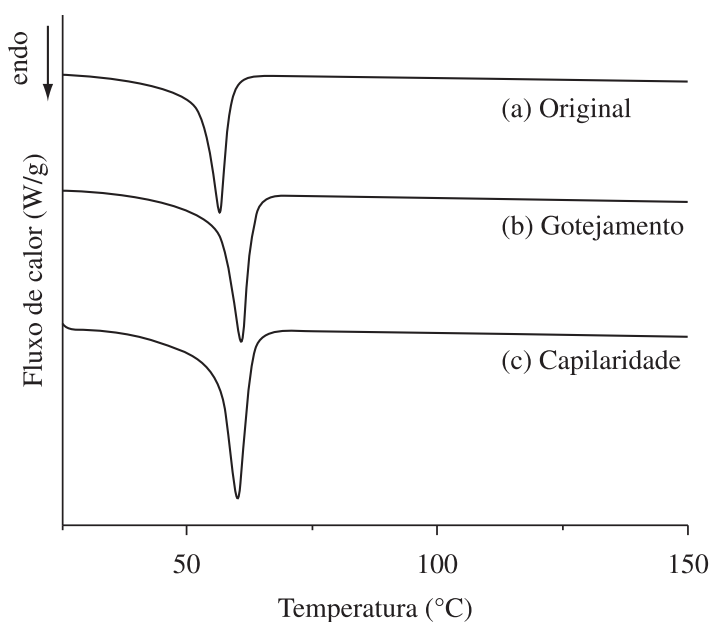

Figura 3. Curvas de DSC de filmes de PCL: a) original; b) biodegradação em coluna de solo, úmida por gotejamento; e c) biodegradação em coluna de solo, úmida por capilaridade, após 30 dias de tratamento microbiano.

Tabela 1. Temperaturas de fusão $T_{f}\left({ }^{\circ} \mathrm{C}\right)$, entalpias de fusão $\Delta \mathrm{H}_{\mathrm{f}}$ e grau de cristalinidade do PCL, tratado em colunas do solo, úmidas por capilaridade e gotejamento.

\begin{tabular}{cccc}
\hline Amostras & $\mathbf{T}_{\mathbf{f}}\left({ }^{\circ} \mathbf{C}\right)$ & $\Delta \mathbf{H}_{\mathbf{f}}\left(\mathbf{J} \cdot \mathbf{g}^{-\mathbf{1}}\right)$ & $\mathbf{X C}(\boldsymbol{\%})$ \\
\hline PCL original & 56 & 75 & 55,0 \\
Capilaridade & 60 & 96 & 70,5 \\
Gotejamento & 61 & 80 & 59,0 \\
\hline
\end{tabular}

Erro $\pm 1{ }^{\circ} \mathrm{C}$.

A degradação térmica de PCL ocorre em uma única etapa, como apresentado na Figura 4. A temperatura inicial da degradação térmica $\left(\mathrm{T}_{\text {onset }}\right)$ e os picos de temperatura máxima de perda de massa $\left(\mathrm{T}_{\text {pico }}\right)$ diminuem em média 12 e $20{ }^{\circ} \mathrm{C}$, respectivamente, para os filmes tratados em solo (sistema gotejamento), Tabela 2. Há uma diminuição da estabilidade térmica em função do aumento do tempo de biodegradação, refletindo a fragilidade da amostra após o biotratamento.

As perdas de massa dos filmes de PCL após tratamento microbiano em coluna de solo estão apresentadas na Figura 5. Observamos que nos filmes de PCL tratados pelo sistema úmido por capilaridade ocorre uma maior perda de massa. Essa diferença pode estar relacionada à umidade, que foi maior no tratamento por capilaridade (48\%), favorecendo a atividade metabólica e a difusão de enzimas microbianas capazes de degradar o poliéster ${ }^{[16,17]}$. Além disso, o tipo de coluna utilizada no experimento, Figura 1b, favorece a concentração de microrganismos ao redor do filme, o que difere do sistema úmido por gotejamento, onde há vários filmes distribuídos no solo, sendo o volume de solo bem maior que no sistema úmido por capilaridade (Figura 1a). Não foi observada nenhuma alteração dos filmes de PCL submetidos ao teste de hidrolise química.

As mudanças na superficie dos filmes de PCL podem ser observadas nas medidas de MEV (Figura 6). Inicialmente a superfície dos filmes poliméricos era lisa e uniforme e com o tempo de tratamento microbiológico, as mudanças morfológicas ficaram mais evidentes. Após a exposição dos filmes por diferentes períodos de tempo ao biotratamento em solo nos diferentes sistemas, as superfícies dos filmes, apresentaram crateras, fissuras e erosão atribuídas à ação dos microrganismos. Os filmes tratados em solução tampão, não apresentaram mudanças morfológicas em relação ao tempo de experimento. A deterioração e/ou erosão da superfície polimérica é um processo interfacial, que depende fortemente dos parâmetros ambientais ${ }^{[18]}$. Como consequências da ação microbiológica surgem
Tabela 2. Valores das temperaturas de inicio $\left(\mathrm{T}_{\text {onset }}\right)$ e máxima velocidade $\left(\mathrm{T}_{\text {pico }}\right)$ para os filmes de PCL biotratado em coluna de solo, úmido por gotejamento.

\begin{tabular}{ccc}
\hline Tempo degradação (dias) & $\mathbf{T}_{\text {onset }}\left({ }^{\circ} \mathbf{C}\right)$ & $\mathbf{T}_{\text {pico }}\left({ }^{\circ} \mathbf{C}\right)$ \\
\hline 0 & 399 & 432 \\
30 & 387 & 415 \\
60 & 387 & 412 \\
\hline
\end{tabular}

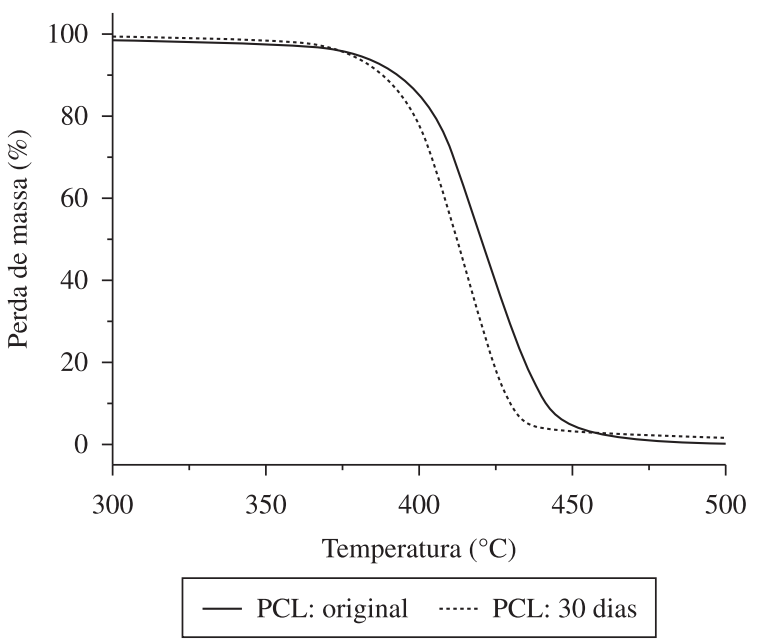

Figura 4. TG: PCL: original e biotratado em coluna de solo, úmida por gotejamento.

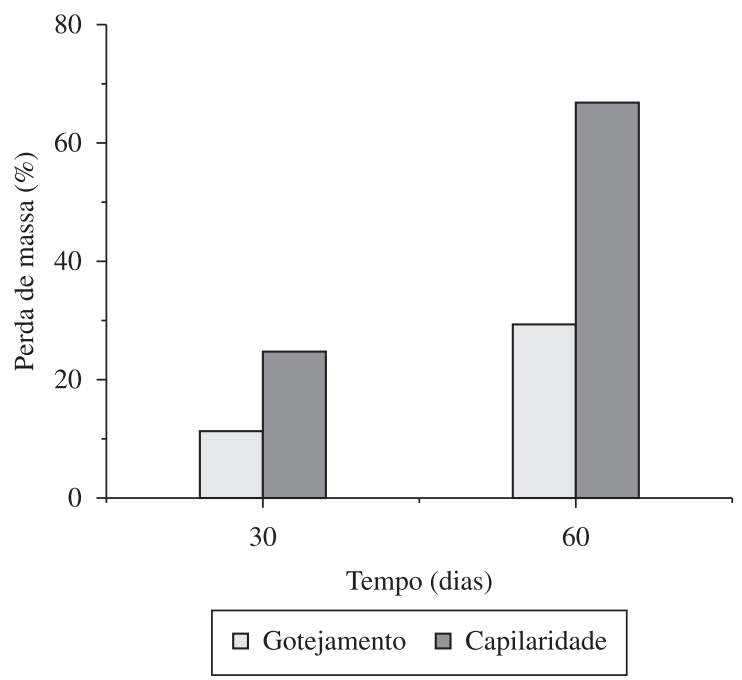

Figura 5. Porcentagem de perda de massa dos filmes PCL após biotratamento em sistemas úmidos por gotejamento e capilaridade.

mudanças nas propriedades da superfície polimérica, ocorrendo a biodegradação nas regiões amorfas assim como finais de cadeia da fase cristalina, tornando os filmes mais quebradiços e frágeis. Os filmes colocados em coluna de solo por sistema de umidade por capilaridade ficaram mais deteriorados, e com grandes orifícios em toda sua extensão. Este tipo de efeito foi observado anteriormente, em filmes de PCL incubados em meio contendo enzimas lipase de Pseudomonas, a $37^{\circ} \mathrm{C}$ por Vidaurre et al. ${ }^{[19]}$, que também concluíram que a degradação enzimática do PCL não alterou sua cristalinidade, devido a biodegradação ocorrer tanto na fase amorfa como na fase cristalina. Além disso, a fase lamelar sofreu modificação, como conseqüência da fragmentação da cadeia, causada pela diminuição da massa molar das cadeias poliméricas ${ }^{[19]}$. 


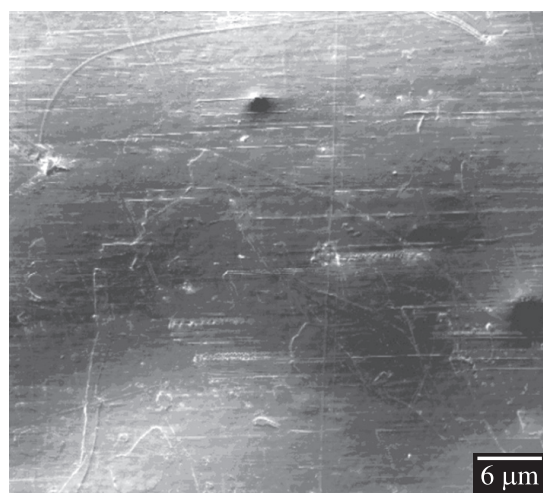

(a)

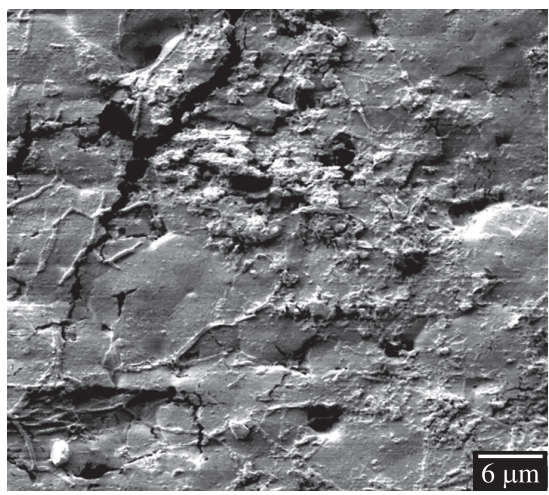

(b)

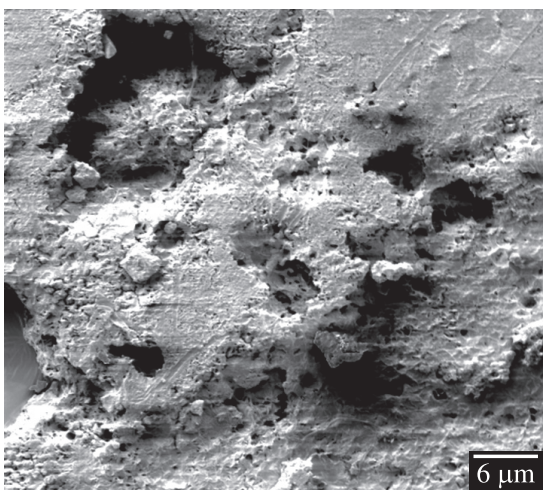

(c)

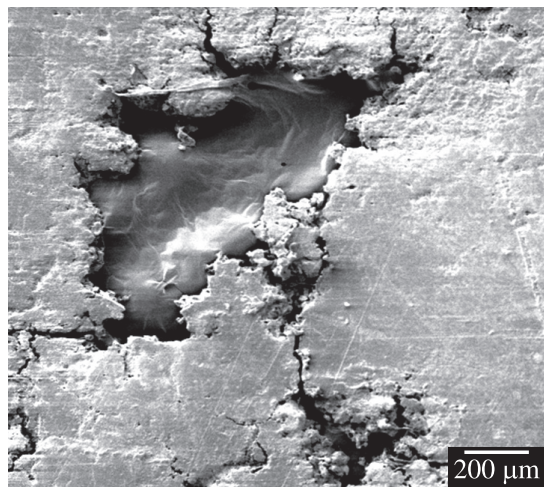

(d)

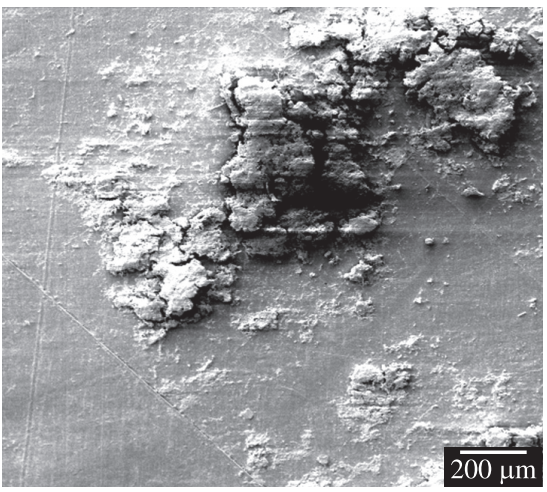

(e)

Figura 6. MEV de filmes de PCL a) original; b) 30 dias capilaridade; c) 60 dias capilaridade; d) 30 dias gotejamento; e e) 60 dias gotejamento.

Os resultados mostraram que a coluna de solo, construída em garrafa PET e umedecida por capilaridade foi mais eficiente na biodegradação de filmes de PCL durante 60 dias do experimento. Isto se deveu à maior concentração de microrganismos ao redor de um único filme, neste caso.

\section{Conclusões}

Este trabalho, mostrou que a biodegradação dos filmes de PCL ocorreu, principalmente na fase amorfa, através de quebras das ligações ésteres da cadeia macromolecular, devido à ação de exo-enzimas dos microrganismos do solo. Os fatores abióticos, tais como temperatura, $\mathrm{pH}$, quantidade de oxigênio, geometria da coluna de solo, umidade são aspectos relevantes para a eficiência da ação microbiológica sobre os filmes poliméricos.

A ação microbiana foi bastante influenciada pelo tipo de coluna de solo, bem como pela umidade, que é a causa da difusão de enzimas e sua consequente ação sobre os filmes de PCL. Estes dois fatores abióticos são relevantes ao processo de biodegradação de filmes poliméricos em solo. A coluna mais eficiente para degradar os filmes de PCL foi a contida em garrafa PET e umedecida por capilaridade.

\section{Agradecimentos}

Os autores agradecem à FAPESP (Processo n ${ }^{\circ}$. 04/14381-7) e ao CNPq (Processo n ${ }^{\circ}$ 142004/2005-7).

\section{Referências Bibliográficas}

1. Gu, J. D.; Ford, T. E.; Mitton, D. B. \& Mitchell, R. - "Microbial corrosion of metals", in: The uhlig corrosion handbook, Revie, W. (ed), Wiley, New York (2000).

2. Shah, A. A.; Hasan, F., Hameed, A. \& Ahmed, S. - Biotechnology Adv., 26, p.246 (2008).
3. Artham, T. \& Doble, M. - Macromolecular Biosci., 8, p.14 (2008).

4. Gu, J. D.; Ford, T. E.; Mitton, D. B.; Mitchell, R. - "Microbial degradation and deterioration of polymeric materials", in: The Uhlig Corrosion Handbook, Revie, W. (ed.), 2nd ed, Wiley, New York (2000).

5. Swift, G. "Non-medical biodegradable polymers: environmentally degradable polymers", in: Handbook of biodegradable polymers, Domb, A. J.; Kost, J. \& Wiseman, D. M. (ed.), Harwood Academic, Amsterdam (1997).

6. Lucas, N.; Bienaime, C.; Belloy, C.; Queneudec, M.; Silvestre, F. \& NavaSaucedo, J. E. - Chemosphere, 73, p.429 (2008).

7. Martins-Franchetti, S. M.; Campos, A.; Egerton, T. A. \& White, J. R. - J. Mater. Sci., 43, p.1063 (2008).

8. Krzan, A.; Hemjinda, S.; Miertus, S.; Corti, A. \& Chiellini, E. - Polym. Degrad. Stabil., 91, p.2819 (2006).

9. Empresa Brasileira de Pesquisa Agropecuária - EMBRAPA. Centro Nacional de Pesquisa de Solos Rio de Janeiro, RJ. "Manual de métodos de análise do solo" (1997).

10. Keroak, D.; Zhao, Y. \& Prud Homme, R. E. - Polymer, 40, p.243 (1998).

11. Eldsäter, C.; Erlandsson, B.; Renstad, R.; Albertsson, A. C. \& Karlsson, S. Polymer, 41, p.1297 (2000).

12. Kesel, C.; Vander Wauven, C. \& David, C. - Polym. Degrad. Stabil., 55, p.107 (1999).

13. Pezzin, A. P. T.; Zavaglia, C. A. C. \& Duek, E. A. R. - Polímeros, 12, p.285 (2002).

14. Vanin, M.; Santana, C. C.; Torriani, I. L.; Privelic, T. \& Duek, E. A. R. Polímeros, 14, p.187 (2004).

15. Tsuji, H. \& Suzuryoshi, K. - Polym. Degrad. Stabil., 75, p.347 (2002).

16. Mochizuki, M. \& Hirami, M. - Polym. Advanced Technol., 8, p.203 (1997).

17. Ter Laak, T. L.; Van Eijkeren, J. C. H.; Busser, F. J. M.; Van Leeuwen, H. P. \& Hermens, J. L. M. - Environ. Sci. Technol., 43, p.1379 (2009).

18. Flemming, H. C. - Polym. Degrad. Stabil., 59, p.309 (1998).

19. Vidaurre, A.; Dueñas, J. M. M.; Estellés, J.M. \& Cortázar, I. C. - Macromol. Symp., 269, p.38 (2008). 